\title{
Virtual Lab Implementation in Science Literacy: Emirati Science Teachers' Perspectives
}

\author{
Saif Saeed Alneyadi ${ }^{{ }^{*}}$ \\ ${ }^{1}$ Department of Curriculum and Instruction, College of Education, UAE University, Al-Ain, UNITED ARAB EMIRATES
}

Received 25 March 2019 • Revised 26 April 2019 - Accepted 10 May 2019

\begin{abstract}
Background: This study explored science teachers' views about the nature and frequency of virtual lab implementation conducted by students and its contribution to developing science instruction and research in the United Arab Emirates (UAE).

Material and Methods: Focus group was employed to collect data through structured interviews. The sample comprised 45 science teachers from 10 intermediate schools. Two questions inquiring into the goals of virtual practical work and its frequency were developed to guide the study.

Results and Conclusions: The results showed that virtual labs had reasonable effects on students' knowledge, skills, attitudes, and achievement as well as innovation. Nonetheless, virtual labs were not used regularly and were only used at a narrow scale; however, they increased students' engagement, motivation, and achievement. Results are discussed in light of reexamining the current practices in terms of implementation, frequency, and country-level large-scale use. It is recommended to maximize virtual labs' use and effectiveness.
\end{abstract}

Keywords: practical work, science teachers, virtual labs, science education

\section{INTRODUCTION}

Practical works either conventional or virtually are integral part in science curriculum and instruction since they are real demonstration and implementation of what students learn. However, the dramatic change and progress of digital technology started to change the nature of practical works and replace them with virtual lab applications. In fact, the significance of practical works was clearly evident in some research studies.

An example was stated by Hegarty-Hazel (1990) who found out that practical work or activities become an essential part of science literacy, curriculum and instruction, with the goal of fostering the scientific thinking skills of students .Additionally, it is assumed that "the best way of learning science is through activities based on a model of scientific inquiry" (Hodson, 1996, p. 116). Practical work is defined as tasks or purposeful activities in which learners in science classrooms observe or manipulate real objects, or they witness real and practical demonstrations. Moreover, practical work serves many purposes. It motivates students by encouraging interest and enjoyment, teaching laboratory skills, enhancing the learning of scientific content knowledge, giving insight into the scientific reasoning and developing expertise in using it, and developing positive 'scientific attitudes', such as openmindedness, objectivity and willingness to suspend sound judgment (Hodson, 1996, p. 90).

It is important to clarify that practical work is not only restricted to laboratory work, despite the latter's importance. That is, practical work is broader than lab activities. Even real-world science is not always practical; it is sometimes abstract or theoretical, exploring ideas for their own sake (Feiman-Nemser \& Floden, 1986). In other word, practical work includes lab activities and demonstrations besides other real life experiences. Since lab resources are not always available, virtual lab apps are the best solutions that meet the needs of the science education and its practical needs and requirements.

(C) 2019 by the authors; licensee Modestum Ltd., UK. This article is an open access article distributed under the terms and conditions of the Creative Commons Attribution License (http://creativecommons.org/licenses/by/4.0/). 《201280225@uaeu.ac.ae (*Correspondence) 


\section{Contribution of this paper to the literature}

- This study aimed at contributing to science education research by addressing the scarcity of research focused on guiding the practice as well as improving the knowledge and experience of science instruction stakeholders. Virtual lab practices, in particular, need to be studied deeply to increase their effectiveness.

Practical virtual and traditional activities have become the core element of science education globally and locally. Moreover, more emphasis has been paid to practical work in science curricula and instruction (Al Naqbi \& Tairab, 2005). Practical work is the heart of a good scientific program and provides students with experiences that are consistent with the science instruction goals. Thus, science teaching and learning can only be done effectively with laboratory learning (Omiko, 2007). This is what Ufondu (2009) has confirmed, emphasizing the effective role of the laboratory in science instruction.

A new trend in the educational philosophy of the United Arab Emirates (UAE) has paid more attention to practical work in science so as to prepare UAE citizens for a post-oil world (National Innovation Strategy, 2015). The UAE aims at reaching the point at which "science; technology and innovation become the real drivers for sustainable socio-economic development." This aspiration builds on innovative initiatives in many sectors, including science education, and focuses on human development and economic diversity for the prosperity future generations. This strategy aspires to enhance science- and technology-based innovation to fulfill national aspirations and to address international challenges; it also enables the UAE to realize huge and rapid leaps in desired change (National Innovation Strategy, 2015). In line with these policies of technology-based innovation, science curricula are designed to enable students to develop scientific work skills by planning and conducting investigations, communicating their knowledge and understanding, and developing scientific thinking and problem-solving techniques (ADEC, 2017).

In response to this strategy, Abu Dhabi Education Council (ADEC) adopted STEM initiative for enhancing science educational services, and consultation as well as providing high-quality science courses. This develops interdisciplinary coursework supplemented with hands on laboratory experience in preparing and training science teachers. It also aims to develop programs that support the preparation of science educators. These strategies have clearly underscored the importance of laboratory learning (ADEC, 2017).

The innovative trend of practical work in science education has been directed towards virtual labs (VLs). In fact, artificial intelligence pursues the creation of intelligent machines that work and react like humans and that simulate, extend and expand human intelligence. Some activities for which artificial intelligence is designed include speech recognition, learning, planning, problem solving, and ability to manipulate and move objects (Xinhua \& Lin, 2018).

Practical scientific work involving AI is best demonstrated by robotics and virtual laboratories. Robotics is an important field related to artificial intelligence. Robots are in need of artificial intelligence to perform tasks such as manipulation and navigation, along with problem solving, motion planning, and mapping. Meanwhile, a virtual lab is a lab or activity involving digital apps simulations, and other manipulative programs used as a replacement for traditional lab activities (Scheckler, 2003). Virtual science labs in general provide more learning opportunities and equal access for school students. Additionally, they can not only provide solutions to lack of facilities and premises, they also introduce students to recent trends in technology and innovation.

\section{STATEMENT OF THE PROBLEM}

It has been noted that science teaching, like real-world science, should be practical. Additionally, scientific experiments and investigations are a central part of real-world scientific activity; therefore, teachers should regard them as an essential and vital part of science education. It is also assumed that practical work should be a major element in school science as well. However, it has noticed that the teachers are not using labs for scientific experiments and investigations effectively in quality and quantity. Even the virtual labs applications are not used regularly or effectively due to some factors that are in need of investigation.

Based on the researcher's experience, practical activities in schools lag behind recent changes and may not be able to instill students with innovative skills that qualify them to participate in the AI era and to cope with innovative progress worldwide. Even the use of VL applications is still developing and is in its infancy.

\section{PURPOSE OF THE STUDY}

The aim of this study was to explore views held by science teachers about the nature of virtual labs implantation carried out by students and its contribution to developing learning in school science in the UAE. Specifically, the study aimed at addressing the following two questions. 
1. How do science teachers in the UAE perceive the goals and reasons for virtual practical work in school?

2. How frequent do science teachers in the UAE use virtual science laboratories?

It is important to investigate science teachers' views so as to contribute to the development of policies and initiatives related to how students learn in labs. It is therefore expected that the findings of this study will contribute to our content knowledge about the practices currently in place in UAE science classes.

\section{LITERATURE REVIEW}

Constructivist theory provides a theoretical framework that served as an appropriate model for analyzing the nature of science learning. It might also enhance instructional strategies and curriculum of science. This focus has been on a developing a constructivist point of view of learning in which students and the teacher are preoccupied with technical and manipulative details that might save their time and energy. Tobin (1990) wrote, "Laboratory activities appeal as a way of allowing students to learn with understanding and, at the same time, engage in a process of constructing knowledge by doing science" (p. 405).

The science laboratory has been defined in different ways. For instance, it has been known as a workshop where scientific practical activities are carried out in a conducive environment in which science equipment, materials, and instruments are housed safely (Ezeliora, 2001). It is also defined as a premise or a period of time equipped and set apart for experimental and practical studies (Omiko, 2007). Thus, science teaching and learning cannot be done without an equipped laboratory. This was confirmed by Ufondu (2009), who emphasized that it is very effective to exploit the laboratory in science instruction. In fact, it has been clarified that "Laboratory activities appeal as a way of allowing students to learn with understanding and, at the same time, engage in a process of constructing knowledge by doing science" (Tobin,1990405). At the beginning of the twenty-first century, an emphasis has been given to rethinking the role and practice of laboratory activities in science. This is especially appropriate due to the increase of content knowledge about human cognition and learning (Brown, Bransford \& Cocking, 2000; Bybee, 1997).

Scientists work in ways where theory comes before and informs practical work. Some major models are the argumentative approach, model-based inquiry, and science in the workplace. The argumentative approach demands evidences as a basis for accepting or rejecting a scientific idea. It also provides an overview of what argumentation means in a practical science context. This approach establishes the relative merits of a claim: through considering the evidence that might support it and that which might not, and through considering whether alternative explanations provide a more holistic understanding. Recent research carried out by Venville and Dawson (2010) showed that the value of improving genetics content knowledge, which was significantly better in their argumentation group compared to the groups that used other approaches.

Model-based inquiry is based upon generating, examining, and revising scientific models, with the aim of evolving evidence-based explanations of the way the natural world activities and practices. This is the way in which many scientists act and react (Windschitl, Thompson, \& Braaten, 2008), so this model inquiry is not only a teaching approach but it is also an authentic representation of how scientific explanations have been produced.

Inquiry is known as a multifaceted activity that comprises making observations, asking questions, testing sources of information to see what is already known, planning investigations, and revising what is already known in light of experimental evidences, using tools to collect, analyze, interpret, and report the data as well as give explanations and predictions, and displaying results (Ma \& Nickerson, 2006). What makes inquiry beneficial is that the laboratory learning environment reinforces the change into a purposeful inquiry that is more student-directed. Besides, science laboratory activities as learning experiences enable students to interact with materials and with models to observe and understand the natural world (Ma \& Nickerson, 2006). One aspect of the new reform has been learning by inquiry, which refers to diverse ways in which scientists study the natural world in an authentic context where learners can study the natural world, propose ideas, and explain and justify statements based upon concrete evidences. In the process, the spirit of science has posed challenges for teachers and learners, since learning by inquiry requires new methods and strategies drawn from different perspectives (Krajcik, Mamlok, \& Hug, 2001).

Science in the workplace is an approach to science lessons that integrates practical activities with a career element. Career work with young people can consist of many different parts. The advice and guidance of the traditional one-to-one interview is only a very small part of how students make choices about their careers. Science teachers should seize opportunities to connect their subject to potential future learning pathways and show pupils where the subject sits in the world of work. There is great potential in being able to integrate practical work with a career element in science education, and this set of resources exemplifies some of the methods in which this can be done in science instruction (Windschitl et al., 2008).

The results of different studies showed that students who completed traditional, hands-on labs performed similar to those students who completed VLs. In contrast, other studies have reported that computer simulation experiments are more effective than traditional hands-on. Rodrigues (1997) reported that many studies investigated 
the use of simulations in science education. In increasing students' interest and engagement in the topic taught during the lesson, it was reported that computer software was more effective than other methods used for the same purpose. Similarly, the use of computer animations is reported to increase students' interest and engagment in lessons (Andoloro et al., 1997; Rodrigues, 1997).

In the related literature, several studies have addressed the use of virtual labs in science. For example, Josephsen and Kristensen (2006) investigated undergraduate chemistry students' response to virtual labs that simulate a 20hour laboratory assignment. The study aimed at identifying the students' experience and knowledge of chemical reactions and the physical and chemical properties of inorganic compounds. The results showed that the students liked and enjoyed this simulation program; they also found it motivating and stated that it generated a lot of experience, which they believed could be remembered more easily (Rauwerda, Roos, Hertzberger \& Breit, 2006).

Results of two studies reported that VLs with simulations were advantageous in rising students' achievements (Joseph, Deborah, \& Edward, 1999; Ozdener \& Erdogan, 2001). Thus, both studies concluded that the material increased the students' achievement level and motivation (Joseph et al., 1999; Ozdener \& Erdogan, 2001).

Tüysüz (2010) carried out a study to explore the impact of virtual chemistry labs on grade nine students' success and attitudes. He collected data using achievement tests and observations. The results revealed that virtual lab software positively impacted the students" success, attitudes, and motivation and enables them recognize the major concepts more easily. The results also showed that VL is an appropriate alternative to a traditional actual lab when, for whatever reason, some experiments cannot be carried out in a real lab.

Harrison, Shallcross, Heslop, Eastman, and Baldwin (2009) conducted a study to identify the impact of VL software on high school students. Data collected from 464 students via achievement tests, interviews, and observation. The results showed that virtual chemistry lab software increased the students' achievement scores related to experimental techniques and that the software helped them focus on the experimental process and fully understood the experiment.

Gorghiu, Gorghiu, Alexandrescu, and Borcea (2009) carried out a study to explore the impact of VL software on teaching "acid-base and neutral solutions" to seventh-grade students. The results showed that VL software impacted the students" satisfaction and efficiency and enabled them to better understand abstract concepts, and that it was also very helpful in hypothesis verification and increasing motivation. Additionally, students took advantage of VLs to sharpen their skills in a risk-free, practice environment.

Although results supported the use of VLs for increasing students' achievement levels and showed that they had positive effects on students' attitudes towards science in general and chemistry in particular. It seems that both virtual laboratories and real lab activities have their merits and demerits. Over more than two decades, several studies have investigated whether computer-simulation experiments or traditional laboratory experiments are more effective for promoting student achievement in science.

One of these studies carried out by Bilek and Skalická (2010) to measure the impact of using real and virtual apps on students' perceptions of VLs. The majority of interviewed chemistry students stated that they preferred rather conducting experiments in real labs and that they did not think that virtual applications were the suitable mediums for gaining scientific experience. Another study conducted by Kerr and Rynearson (2004) compared the achievement among students instructed through conventional labs versus virtual chemistry labs. The results agreed with Bilek and Skalická (2010) whose results had no significant differences in achievement gain scores between students using traditional labs and who used virtual apps. Therefore, instructional materials developed for use on computers can be a solution for schools that have no science labs but do have a computer cluster or laboratory (Saka \& Yilmaz, 2005).

Though out the review of the studies, it is clear in most studies that VL has positive impact on students' achievement and attitude towards science as well as enhancing students' learning (Gorghiu et al, 2009; Harrison et al, 2009; Joseph et al., 1999; Joseph, Deborah, \& Edward, 1999; Josephsen \& Kristensen, 2006; Ozdener \& Erdogan, 2001; Rauwerda et al., 2006; Tüysüz, 2010). In contrast, a few studies had the opposite results and argued for using traditional labs (Bilek \& Skalická, 2010; Kerr \& Rynearson, 2004). This urges for more studies to explore the impact of VL implementation on students 'learning. Locally, the VL is still not spreading at the wide range and needs more research to guide the practice. 


\section{METHODOLOGY}

This section highlights the study design, sampling of the study as well as the participants. Then, the instrument used will be described. Next, data collection procedures and analysis are discussed.

\section{Design}

A qualitative research focus group design was employed in the form of structured interviews and categorization of data. Structured interviews were employed for collecting in-depth data about the use of VLs. The researcher believes that the participants' ideas and interests are better generated by interactive dialogues between the researcher and participants. Thus, an interview technique was used to elicit detailed and accurate description of science teachers' views of the frequency and goals of using VLs.

\section{Sample of the Study}

The population of this study consisted of both female and male science teachers in Al-Ain Education Office. According to a formal source from Al-Ain Education Office, they have about 150 science teachers across 22 schools. Sample selection was done randomly to include a reprehensive sample of cycle 2 science teachers in public schools. The randomly-selected participants included 45 people from ten schools; five boys' schools and five girls' schools. About 23 males and 22 females participated in the structured interviews.

\section{Instrument}

This research employed one main instrument, the structured interview. The interviewees had to answer major questions about participants and about their views on the frequency and goals of using VLs. The main questions in the interview included "What are the five goals of using virtual practical work in school?" and "How frequent do you use virtual science laboratories? ". Then, these questions followed by follow up questions.

The validity of the instrument was established by asking three science teachers and three science educators to review the interview questions in light of conceptual frameworks related to the goals and role of VLs in science education.

\section{Data Collection and Analysis}

Data collection started by setting the stage for interviews, ten schools was selected randomly from 22 schools. Then, 45 participants who were selected from these schools. The participants were divided into 10 focus groups ranging from 4 to 5 teachers. The teachers were asked to voluntary participate in the interview and their personality would be confidential. Additionally, a formal permission from the educational zone was obtained to access the schools.

The interviews were audio-recorded and later transcribed and coded for relevant themes. The core themes included five categories; scientific knowledge, scientific process and skills, intellectual abilities, attitudes, and innovation. The interview data regarding the most important five goals/reasons for doing virtual practical work in school laboratories were classified into the core themes mentioned previously as well as direct quotations to support the themes. The transcripts were sent again to the participants for reviewing. The other part of the interview addressed frequency of use (daily, weekly, monthly, termly, and yearly). This data were presented in table that included frequency and percentage of VLS uses. Additionally, the transcripts were subjected to a peer reviewer.

\section{RESULTS OF THE RESEARCH}

\section{Question 1}

The first research question aimed at exploring how UAE science teachers perceive the goals and reasons for doing practical work in VL applications. The goals were classified into five core ideas and themes, including knowledge, scientific skills and process, intellectual abilities, attitudes, and innovation.

\section{Knowledge}

More than half participants agreed that the use of VLs increased their scientific content knowledge. One to two responses were observed in each knowledge subcategory, including nature of science, basics of science, scientific concepts, subject matter regardless of language barrier, removal of misunderstanding or ambiguity, improved mastery of subject matter, and transformation of theoretical into practical knowledge. Additionally, the responses 
Table 1. Frequency \& Percentage of Virtual Lab Use from Teachers' Perspectives

\begin{tabular}{lcc}
\hline Uses & Frequency & Percentage \\
\hline Daily & 0 & 0 \\
\hline Weekly & 3 & 7 \\
\hline Monthly & 5 & 11 \\
\hline Every Semester & 6 & 13 \\
\hline Annually & 8 & 18 \\
\hline Not at all & 23 & 51 \\
\hline Total & 45 & 100 \\
\hline
\end{tabular}

numbered from five to seven in each of the four main science subjects, the highest being in biology (7) and the lowest in geology (5).

\title{
Scientific Skills
}

About (56\% the participants reported that using VLs increased students' scientific skills. One to three responses were observed in each of the subcategories of scientific skills: investigative skills, enquiry, observation, measurement, accuracy, and planning. Moreover, the responses ranged from four to eight in the four main science subjects; the highest response (8) was reported in biology and the lowest (4) in geology.

\section{Intellectual Skills}

About $60 \%$ of participants reported that using VLs increased students' intellectual skills. Two or three responses were observed in each of the three subcategories: critical-thinking and decision-making problem-solving, skills. Moreover, responses numbered from five to eight in the four main science subjects; the highest response (8) was reported in biology and the lowest (5) in geology.

\begin{abstract}
Attitudes
About $60 \%$ of the participants reported that using VLs developed positive attitudes towards practical work activities, including cultivating interest in science and science learning, ensuring enjoyment, motivating students to think about life using science, and making lessons fun and interactive. Two or three responses were observed in each subcategory of attitude. Moreover, responses numbered from six to eight in the four main science subjects; the highest response (8) was reported in biology and the lowest (6) in geology.
\end{abstract}

\section{Innovation}

About $65 \%$ of participants reported that VLs increased students' innovation skills and abilities, encouraging students to be inventors, helping them to discover their innovations and talents, promoting originality and inventiveness in their practical work, and helping them to act on creative ideas to make tangible and useful contributions to the domains in which innovation occurs. Two to three responses were observed in each of the five subcategories of innovation. Moreover, the responses numbered from six to nine in each of the four main science subjects; the highest response (9) was reported in biology and the lowest (6) in geology.

To sum up, the percentages were respectively sequenced as follows: Innovation (65\%) Attitudes (60\%), Intellectual Skills (60\%), Scientific Skills (56\%), and Knowledge (53\%).

\section{Question 2}

The teachers were asked to respond to the second research question about the extent to which they use VLs and robotics during practical work. The use of VLs and robotics was very low, and most teachers responded that they used these programs very rarely or never (Table 1 ).

Table 1 displays the results of the second research questions, which revealed that more than half of the science teachers reported that they did not use VLs at all (51\%), regardless of their gender. However, only eight teachers used VLs on a weekly or monthly basis. The researcher clarified with the teachers that use of VLs and robotics, areas that are part of the AI wave sweeping across industries worldwide, is low. Most teachers agreed that they have not been trained to integrate VL software into lessons, or even that they were not provided with them. Additionally, only two male teachers reported that they used robotics in their instruction very often, and they added that this was due was because of their own initiative, not because they were instructed by the school or educational zone. 
One female teacher reported that she has the skill and will to integrate recent technologies into her instruction; however, she had faced many barriers, like high teaching load and lack of availability of software applications and hardware, professional training, curriculum planning, and support and funding. Another female teacher stated that she is interested in developing herself and her students, and that she supports use of VL applications, as they help engage students and give them opportunities to focus on the experimental process, not on the equipment and tools; moreover, the students may repeat experiments as many times as needed if they do not understand. This teacher also added, "I have observed that VL applications increase the students' science scores and achievement."

A male science teacher stated, "I am the only science teacher using robotics in practical work. I asked the students to plan and conduct an experiment to measure the temperature using robotics. The students were very engaged, and they reported that they were very enthusiastic and learning very well. They were also required to use VL applications during science lessons and while designing their projects."

One male teacher also reported, "I had tried to use VL applications twice and found that my students preferred physical labs to VLs, since students desired to do the experiments as they are in nature, where there are sensations like touching or smelling."

\section{SUMMARY OF THE RESULTS}

The results of the first research question revealed that science teachers responded in different percentages to the importance of practical work activities using VLs in increasing students' scientific knowledge, scientific process and skills, intellectual abilities, attitudes, and innovation. Additionally, the qualitative data collected by the interview showed that most responses ranged between $53 \%$ and $65 \%$. However, the highest percentage reported was for innovation $(65 \%)$ and the second highest for attitudes $(60 \%)$. The lowest percentage was observed for knowledge. This can be attributed to a new trend in the UAE to focus on VLs in science literacy so as to prepare the UAE for a post-oil world (National Innovation Strategy, 2015).

As for the second research question, the results showed that most teachers reported that practical VL implementation remains in its infancy. More than half of the teachers, regardless of gender, reported that they have used VL software narrowly, in individual cases, or not at all. This may be due to different barriers including lack of software resources, lack of training, and academic decisions by curriculum designers or educational policy makers. Based on these responses, VL applications have either not been used or implemented effectively, or have not been used at all. However, the few teachers who used virtual applications or robotics reported that VL applications increased students' engagement and achievement.

\section{CONCLUSION}

To could be concluded that more than half of teachers participating in the study agreed that practical work activities using VLs had positive impact on increasing students' scientific knowledge, scientific process and skills, intellectual abilities, attitudes, and innovation. However, their uses of VLs are still poor and limited. It is noticed that the results of the first research are not in line of the results of the second research questions.

\section{DISCUSSION}

Despite the agreement of more than half of the teachers about the importance of using virtual labs and their impact on students' achievement, attitudes and skills, their real practices contradicted their beliefs since their uses of VLs are not regular. This may refer to different factors as availability of software, hardware school culture, lack of resources or even their attitudes.

Some results were congruent with Tüysüz (2010), who revealed that VL software positively impacted students' achievement and motivation. Additionally, the results of the current study regarding the positive impact of VL software on students' achievement in science were similar to the results of Harrison (2009).

Overall, the teachers reported that VLs had reasonable effected on students' knowledge, skills, attitudes, and achievement, as well as innovation. However, VL applications have not been used regularly, or at all, and their use has been limited to individual initiatives by teachers.

It seems that more than half of the teachers agreed about the importance of VLs in increasing students' scientific knowledge, scientific process and skills, intellectual abilities, attitudes, and innovation. However, most of the teachers were not using VLs either daily or weekly. This may refer to the lack of resources or even the digital culture in the schools has not reinforced the Technology integration in practice. This may be also caused by teachers' attitude towards digital technology due to teachers' technological proficiency or acceptance from side. 


\section{RECOMMENDATIONS AND IMPLEMENTATIONS}

In light of the results, some recommendations and implementations are suggested.

1. Science teachers need to maximize daily virtual practical work.

2. More focus must be given to developing students' knowledge and cognitive abilities, including analysis, synthesis, innovation, and creation.

3. Future research studies should include other educational cycles, like those of high schools and other areas.

4. Schools are invited to teach the importance of VL to enhance students' innovation skills.

5. Teachers need to carry out science lessons in nontraditional classrooms through virtual technology integration.

6. Schools should be provided with VL applications and all the needed technology.

7. Decisions need to be made to spread digital culture in science teaching.

8. Teachers need professional development programs to enhance their digital and professional experience in virtual labs apps.

\section{ACKNOWLEDGEMENTS}

Many thanks are extended for the staff and professors in the College of Education at UAE University for their ongoing support and encouragement.

\section{REFERENCES}

ADEC. (2017). ADEC 6-9 science curriculum framework. Retrieved from https:/ / ntwasol.files.wordpress.com/2012/02/grades_6-9_science_curriculum_v51.pdf

Akani, O. (2015). Laboratory teaching: Implication on students' achievement in chemistry in secondary schools in Ebonyi State of Nigeria. Journal of Education and Practice, 6(30), 206-208. Retrieved from https:/ / files.eric.ed.gov/fulltext/EJ1081346.pdf

Al-Naqbi, A. K., \& Tairab, H. H. (2005). The role of laboratory work in school science: Educator's and student's perspectives. Journal of the Faculty of Education, 18(22), 19-35. https:/ / doi.org/10.5032/jae.2014.01167

Andoloro, G., Bellamonte, L., \& Sperandeo-Mineo, R. M. (1997). A computer-based learning environment in the field of Newtonian mechanics. International Journal of Science Education, 19(6), 661-680. https:/ / doi.org/10.1080/0950069970190604

Bilek, M., \& Skalická, P. (2010). Combination of real and virtual environment in early chemistry experimental activities. In DOLINŠEK, S., LYONS, T. (eds.) Socio-cultural and human values in science and technology education - XIV. IOSTE Symposium Proceedings, Ljubljana: Institute for Innovation and Development of University, 185 - 192. Retrieved from http:/ /lide.uhk.cz/prf/ucitel/bilekma1/moznosti/text/sbor_2010_2. pdf

Bybee, R. W. (1997). Achieving scientific literacy: From purposes to practices. Westport, CT: Heinemann. Retrieved from https://eric.ed.gov/?id=ED461491

Cairns, D. (2016). Exploring the Relations of Inquiry-Based Teaching to Science Achievement and Dispositions in 54 Countries. Research in Science Education, 49, 1-23. https:/ / doi.org/10.1007/s11165-017-9639

Ezeliora, R. (2001). A guide to practical approach to laboratory management and safety precautions. Congregation of the Daughters of Divine Love. Enugu: Divine Love Publishers.

Feiman-Nemser, S., \& Floden, R. E. (1986). The cultures of teaching. In M. C. Wittrock (Ed.) Handbook of research on teaching (3rd ed.) (pp. 505-526). New York: Macmillan.

Geban, O., Askar, P., \& Ozkan, İ. (1992). Effects of computer simulations and problem solving approaches on high school students. Journal of Educational Research, 86(1), 5-10. https:/ / doi.org/10.1080/00220671.1992.9941821

Gorghiu, L. M., Gorghiu, G., Alexandrescu, T., \& Borcea, L. (2009). Exploring chemistry using virtual instrumentation - Challenges and successes. Research, Reflections and Innovations in Integrating ICT in Education, 1(1), 371-375. Retrieved from https://www.worldcat.org/title/research-reflections-andinnovations-in-integrating-ict-in-education-vol-1/oclc/440002499 
Harrison, T. G., Shallcross, D. E., Heslop, W. J., Eastman, J. R., \& Baldwin, A. J. (2009). Transferring best practice from undergraduate practical teaching to secondary schools: The dynamic laboratory manual. Acta Didactica Napocensia, 2(1), 1-8. Retrieved from https:/ / files.eric.ed.gov/fulltext/EJ1052372.pdf

Hounshell, P. B., \& Hill, S. R. (1989). The microcomputer and achievement and attitudes in high school biology. Journal of Research in Science Teaching, 26(6), 543-549. https:/ / doi.org/10.1002/tea.3660260606

Joseph, L. G., Deborah, H., \& Edward, J. S., (1999). User-centered design and evaluation of virtual environments. IEEE Computer Graphics and Applications, 51-59. Retrieved from https:/ / pdfs.semanticscholar.org/83e1/dae991f9dd6238135e39b031fddb3e0155ea.pdf.

Kerr, M. S., Rynearson, K., \& Kerr, M. C. (2004). Innovative educational practice: Using virtual labs in the secondary classroom. The Journal of Educators Online, 1(1), 1-9. https:/ / doi.org/10.9743/JEO.2004.1.3

Krajcik, J., Mamlok, R., \& Hug, B. (2001). Modern content and the enterprise of science: Science education in the twentieth century. Yearbook of the National Society for the Study of Education, 1, 205-238.

Lunetta, V. N., Hofstein, A., \& Clough, M. P. (2007). Teaching and learning in the school science laboratory. An analysis of research, theory, and practice. Chemistry Education Research and Practice, 8(2), 105-107.

Ma, J., \& Nickerson, J. V. (2006). Hands-on, simulated, and remote laboratories: A comparative literature review. ACM Computing Surveys (CSUR), 38(3), 7. https:/ / doi.org/10.1145/1132960.1132961

Millar, R. (2004). The role of practical work in the teaching and learning of science. Paper prepared for the Committee. High School Science Laboratories: Role and Vision, 1-24. Retrieved from https:/ / sites.nationalacademies.org/cs/groups/dbassesite/documents/webpage/dbasse_073330.pdf

National Innovation Strategy. (2015). Science, technology and innovation (STI) policy. Retrieved from http://www.uaeinnovates.gov.ae/innovation-ecosystem/sti-policy

Omiko, A. (2007). Job orientation and placement: The role of science education in a developing economy. Abakaliki: Larry and Caleb Publishing House. https:/ / doi.org/10.12691/education-5-7-4

Omiko, A. (2015) chemistry teachers' attitude and knowledge of the use of information communication technology (ICT) in chemistry instruction delivery at the secondary school level in Ebonyi State of Nigeria. Journal of Curriculum Organization of Nigeria (CON) Imprint.

Ozdener, N., \& Erdoğan, B. (2001). Computer-aided design and development of simulation (ss. 235-241). Fen Bilimleri Egitimi Sempozyumu ve Fuari. [Science Education Symbolism \& Fair ] Maltepe University, Istanbul, Turkey. https:/ / doi.org/10.2174/1872208311307010005

Rauwerda, H., Roos, M., Hertzberger, B., \& Breit, T. (2006). The promise of a virtual lab in drug discovery. Drug Discovery Today, 11(5-6), 228-236. https:/ / doi.org/10.1016/S1359-6446(05)03680-9

Rodrigues, S. (1997). Fitness for purpose: A glimpse at when, why and how to use information technology in science lessons. Australian Science Teachers Journal, 43(2), 38-39. Retrieved from https://www.learntechlib.org/p/ 83983/

Saka, A. Z., \& Yilmaz, M. (2005). Computer-assisted physics teaching material development and implementation. TOJET: The Turkish Online Journal of Educational Technology, 4(3), 122-128.

Scheckler, R. K. (2003). Virtual labs: A substitute for traditional labs? International Journal of Developmental Biology, 47(2-3), 231-236. Retrieved from http://www.ijdb.ehu.es/web/paper/12705675/virtual-labs-a-substitutefor-traditional-labs

Tamir, P. (1989). Training teachers to teach effectively in the laboratory. Science Education, 73(1), 59-69. https://doi.org/10.1002/sce.3730730106

Tobin, K. (1990). Research on science laboratory activities: In pursuit of better questions and answers to improve learning. School Science and Mathematics, 90(5), 403-418. https:/ / doi.org/10.1111/j.1949-8594.1990.tb17229.x

Tüysüz, C. 2010. The effect of the virtual lab on students' achievement and attitude in chemistry. International Online Journal of Educational Sciences, 2(1), 37-53. Retrieved from http:/ / citeseerx.ist.psu.edu/viewdoc/download? doi=10.1.1.657.6059\&rep=rep1\&type $=$ pdf

Ufondu, N. U. (2009). The role of the laboratory on the academic achievement of students in biology in Abakaliki Education Zone of Ebonyi State (Unpublished B.Sc. Ed thesis). Ebonyi State University, Abakaliki.

Venville, G. J., \& Dawson, V. M. (2010). The impact of a classroom intervention on grade 10 students' argumentation skills, informal reasoning, and conceptual understanding of science. Journal of Research in Science Teaching, 47(8), 952-977. https:/ / doi.org/10.1002/tea.20358 
Windschitl, M., Thompson, J., \& Braaten, M. (2008). Beyond the scientific method: Model-based inquiry as a new paradigm of preference for school science investigations. Science Education, 92(5), 941-967. https://doi.org/10.1002/sce.20259

Xinhua, L., \& Lin, X. (2018). Research on artificial intelligence-based education in the era of internet+. In 2018 International Conference on Intelligent Transportation, Big Data E Smart City (ICITBS) (pp. 335-338). IEEE. https://doi.org/10.1109/ICITBS.2018.00092

\section{http://www.ejmste.com}

